\title{
Períodos Secos no Estado do Paraná
}

\author{
Flávia Galvanini Salton ${ }^{1,2}$ (D), Heverly Morais ${ }^{1}$, Marciel Lohmann ${ }^{2}$ \\ ${ }^{1}$ Agrometeorologia, Instituto Agronômico do Paraná, Londrina, Paraná, Brasil. \\ ${ }^{2}$ Departamento de Geociências, Universidade Estadual de Londrina, Londrina, Paraná, Brasil.
}

Recebido em: 30 de Outubro de 2017 - Aceito em: 25 de Fevereiro de 2020

\begin{abstract}
Resumo
A caracterização climatológica espacial, temporal e quantitativa de períodos secos pode minimizar os prejuízos na agricultura, pois o mapeamento da seca é uma importante ferramenta para avaliar impactos e propor alternativas de adaptação e mitigação de seus efeitos. O propósito deste trabalho é mapear e analisar alguns aspectos dos períodos secos ocorridos no estado do Paraná, Brasil. Observa-se que os episódios de períodos secos diminuem à medida que aumenta sua duração. No Paraná o número de períodos secos diminui conforme aumenta a latitude do estado. O maior número de períodos secos ocorre nos meses mais frios no Paraná (maio a agosto). As secas severas e moderadas ocorrem mais frequentemente na condição de La Niña, enquanto que as mais fracas são registradas em El Niño. Não há tendência de aumento ou redução de períodos secos nas diferentes regiões do Paraná.
\end{abstract}

Palavras-Chave: seca, agricultura, fenômeno ENOS, tendência climática.

\section{Dry Periods in the State of Paraná, Brazil}

\begin{abstract}
The spatial, temporal and quantitative characterization of dry periods can minimize the losses in agriculture, since the drought mapping is an important tool to evaluate impacts and propose alternatives of adaptation and mitigation of their effects. The purpose of this work is to map and analyze some aspects of the dry periods occurred in the state of Paraná, Brazil. It is observed that episodes of dry periods decrease as their duration increases. In Paraná the number of dry periods decreases as the latitude of the state increases. The highest number of dry periods occurs in the colder months in Paraná (May to August). Severe and moderate droughts occur more frequently in the La Niña condition, while the weaker ones are recorded in El Niño. There is no tendency to increase or reduce dry periods in the different regions of Paraná.
\end{abstract}

Keywords: dry, agriculture, ENSO phenomenon, climate trend.

\section{Introdução}

A agricultura, principal atividade econômica do estado do Paraná, é altamente dependente do clima, em especial das precipitações. A ocorrência de períodos secos, dependendo da sua duração e estádio de desenvolvimento da planta, ocasiona impactos negativos na produtividade das culturas, visto que a água desempenha funções vitais nos processos metabólicos das plantas. $\mathrm{O}$ efeito da precipitação na agricultura é tão evidente que estudos de estimativas de previsão de safra de grãos são baseados essencialmente na previsão climática de chuva durante o ciclo da cultura. Hoogenboom (2000) relata que $80 \%$ da variabilidade da produção agrícola podem ser explicadas pelas condições do tempo, sendo a seca responsável por $56 \%$ de perdas por intempéries climáticas. Devido a ocorrência de secas, o Paraná e o Rio Grande do Sul deixaram de colher juntos 7 e 11,5 milhões de toneladas de soja nas safras de 2003/2004 e 2004/2005, respectivamente (Farias, 2006).

$\mathrm{O}$ zoneamento agrícola indica as melhores épocas de semeadura, evitando que as fases de grande demanda hídrica coincidam com a época de ocorrência de maior risco de períodos secos (MAPA, 2017), no entanto, devido à variabilidade climática interanual, isso nem sempre acontece na prática. As regiões norte e noroeste do estado

Autor de correspondência: Flávia Galvanini Salton, flavinha_salton@hotmail.com. 
do Paraná são frequentemente acometidas por secas de leve intensidade, por isso recomenda-se técnicas de manejo para minimizar ou evitar danos e prejuízos agrícolas provocados pela seca como: escalonamento da semeadura, cultivares mais adaptadas à seca e práticas que otimizam a conservação da água e solo como plantio direto, uso de plantas de cobertura, terraceamento, plantio em nível, sistemas agroflorestais, rotação e consorciação de culturas, irrigação, entre outros. Em adição, em alguns locais muito secos e de solos com baixa fertilidade do noroeste paranaense, recomenda-se o cultivo de culturas perenes, como as frutíferas, que toleram mais o déficit hídrico devido suas raízes mais profundas. Por exemplo, o cultivo de abacaxizeiro na região do arenito Caiuá apresenta alta viabilidade econômica e alta competitividade em relação às regiões tradicionalmente produtoras e é uma alternativa para reverter as crescentes condições de degradação dos solos e pastagens no noroeste do Paraná (Leal et al., 2009).

De acordo com Mota e Agendes (1986) a principal causa da seca é a falta de processos físicos e dinâmicos capazes de produzir movimentos ascendentes na atmosfera que provocam as chuvas. No estado do Paraná há grande variabilidade espacial e temporal de chuvas devido ao clima transicional, sendo influenciadas principalmente pelas seguintes massas de ar: Equatorial continental, Tropical continental, Tropical atlântica e Polar atlântica (Nimer, 1989). Tais massas de ar, associadas ao relevo, continentalidade e oceanidade, alteram significativamente as condições do tempo no estado (Ferreira, 2007; Kobiyama et al., 2006).

Além disso, de acordo com Reboita et al. (2010), a precipitação da região sul do Brasil está associada a outros sistemas atmosféricos: sistemas frontais que se deslocam do Pacífico, passam pela Argentina e seguem para o nordeste do Brasil; ciclones e frentes frias que se desenvolvem nessa região devido à presença de vórtices ciclônicos ou cavados em altos níveis sobre a costa oeste da América do Sul vindos do Pacífico e também devido a condições frontogenéticas e/ou ciclogenéticas originadas na própria região; complexos convectivos de mesoescala; sistemas ciclônicos em níveis médios conhecidos como vírgula invertida; e bloqueios atmosféricos. Somados a atuação de sistemas de circulação locais e a influência indireta da Zona de Convergência do Atlântico Sul (ZCAS).

Os regimes das precipitações em diferentes regiões do planeta são influenciados pelas perturbações de larga escala do fenômeno El Niño Oscilação Sul (ENOS) que é uma oscilação acoplada do oceano-atmosfera, produzindo alterações na Temperatura da Superfície do Mar (TSM), na pressão, no vento e na convecção tropical, principalmente no oceano Pacífico (Grimm, 2009b). O fenômeno apresenta duas fases: uma quente, o El Niño, e outra fria, a La Niña. De acordo com Pscheidt (2006), os episódios El Niño são caracterizados pela presença de águas mais quentes no Pacífico equatorial leste, enfraquecimento dos ventos de leste assim como do gradiente leste-oeste de TSM, com predominância das anomalias positivas de TSM no Pacífico leste, abaixamento de pressão com convecção anômala no Pacífico oriental e aumento de pressão com subsidência anômala no Pacífico oeste, Indonésia e Austrália. Durante a fase de La Niña, fase oposta ao El Niño, os ventos equatoriais de leste são mais intensos do que em condições normais, assim como os gradientes leste-oeste de pressão em superfície e TSM são reforçados.

As análises dos impactos do ENOS no sul do Brasil sugerem que em condições de El Niño ocorrem excesso de precipitação em relação à normal climatológica, enquanto que em La Niña ocorrem redução da precipitação (Ropelewski e Halpert, 1989 apud Salini, 2011). Segundo Nascimento Júnior e Sant'Anna Neto (2015), no estado do Paraná os sinais dos padrões ENOS são mais discretos devido ao clima tropical e transicional.

Além da variabilidade das chuvas provocadas por fenômenos naturais, têm-se investigado nos últimos tempos causas antropogênicas na alteração da climatologia da precipitação. Eventos climáticos extremos estão aumentando, incluindo secas mais frequentes e prolongadas, provavelmente devido às mudanças climáticas e aquecimento do planeta (Stokstad, 2004; Schiermeier, 2006). Segundo CEDA (2014), prejuízos econômicos relacionados com o clima têm apresentado tendência crescente nas últimas décadas.

Compreender o fenômeno da seca, suas possíveis causas e impactos são importantes para estabelecer a segurança hídrica e propor alternativas para adaptação e mitigação dos seus efeitos. Assim, a caracterização quantitativa, espacial e temporal de períodos secos pode minimizar os prejuízos gerados por essa intempérie, incluindo os relacionados à agricultura.

Este trabalho tem como objetivo analisar climatologicamente os períodos secos no estado do Paraná quanto a intensidade, espacialidade, associação com o fenômeno ENOS e tendências climáticas.

\section{Material e Métodos}

Foram utilizados dados diários de precipitação registrados no período de 1977 a 2015 de cento e quarenta e duas estações meteorológicas do Paraná (Fig. 1), pertencentes a diferentes instituições: Instituto Agronômico do Paraná - IAPAR; Agência Nacional de Águas - ANA; Instituto das Águas do Paraná; Companhia Paranaense de Energia - COPEL; e Instituto Nacional de Meteorologia INMET.

Considerou-se como período seco o número de dias consecutivos sem chuva (inferior a $1 \mathrm{~mm}$ ). Os dados foram agrupados em três intensidades de acordo com a duração dos períodos secos: fraca $\geq 10<20$ dias; modera- 


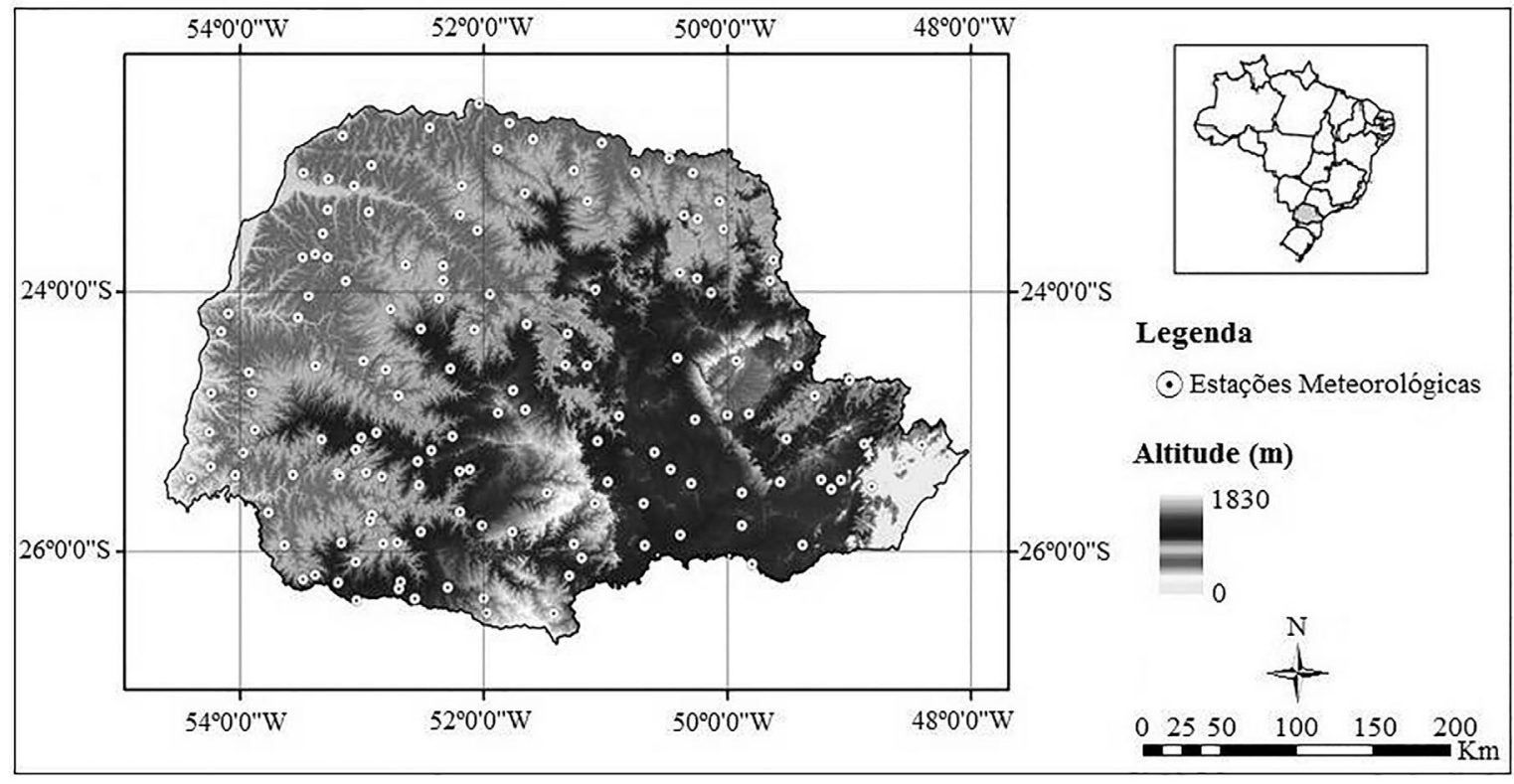

Figura 1 - Localização geográfica e relevo de 142 estações meteorológicas do Paraná.

da $\geq 20<30$ dias; e severa $\geq 30$ dias. Para a definição das classes de períodos secos utilizou-se como critério o conceito de seca agrícola, que liga várias características da seca meteorológica (ou hidrológica) aos impactos agrícolas, com foco na escassez de precipitação, considerando basicamente os períodos médios relacionados à disponibilidade de água no solo para suportar o crescimento e desenvolvimento da maioria das culturas agrícolas (WMO, 2005). O mês considerado do período seco foi no seu término, mesmo que este iniciasse no mês anterior.

Foi realizada a caracterização climatológica espacial do total anual e mensal de períodos secos registrados no estado do Paraná para cada intensidade, expressos em mapas gerados no software ArcGIS 10.2.2, utilizando a interpolação dos dados pelo método de krigagem.

Os períodos secos foram associados com os eventos de El Niño, La Niña e neutralidade. Para cada um desses eventos e intensidades calculou-se a frequência relativa, que é a porcentagem de ocorrência de períodos secos em cada evento em relação à quantidade total desses períodos registrados em cada intensidade. Também foi calculada a frequência absoluta, que é a porcentagem de ocorrência de cada evento no período analisado (1977-2015), independente da ocorrência de períodos secos. As informações sobre o fenômeno ENOS foram extraídas do National Oceanic and Atmospheric Administration (NOAA, 2017). A caracterização do ENOS é feita por meio de índices, como o Índice de Oscilação Sul (IOS), que é calculado pela diferença de pressão entre duas regiões distintas: Taiti e Darwin e os índices nomeados Niño (Niño 1+2, Niño 3, Niño 3.4 e Niño 4) baseados na medição da temperatura da superfície do mar (TSM) em diferentes regiões do Pacífico Equatorial.
Foram realizadas análises de regressão para verificar tendências na alteração do número de períodos secos registrados ao longo do período (1977 a 2015) para cada intensidade e mesorregião do estado. O coeficiente de determinação R2 e inclinação do coeficiente angular foram utilizados como critérios de verificação da significância.

\section{Resultados e Discussão}

$\mathrm{Na}$ análise das intensidades das secas ocorridas no estado do Paraná, observa-se que conforme aumentou a duração diminuiu o número de ocorrências (Fig. 2). As quantidades de eventos variaram de 116 a 239 períodos secos de intensidade leve (76\%); 13 a 79 eventos de seca moderada (17\%); e 2 a 52 eventos de períodos secos intensos (7\%). Nota-se que no Estado do Paraná as secas são pouco frequentes, principalmente as mais prolongadas, pois em 39 anos de análise ocorreram em média 5,1 e 0,5 episódios de secas leve, moderada e severa por ano, respectivamente. Assad et al. (1993), Carvalho et al. (2013) e Oliveira et al. (2015), em estudos sobre veranico, também observaram que a frequência dos eventos de seca diminuía à medida que aumentava a duração.

Quanto à espacialização, de modo geral, os períodos secos no Paraná aumentaram de leste para oeste (Fig. 2), ou seja, houve mais secas a medida que se distanciou do oceano e a altitude do estado decresceu (Fig. 1). Por exemplo, a região noroeste, que é a mais baixa e mais distante do oceano, apresentou os maiores registros de períodos secos. Mendonça e Danni-Oliveira (2007) e Vanhoni e Mendonça (2008) relatam que a ocorrência de períodos secos está fortemente associada ao relevo e a maritimidade/continentalidade, que por sua vez influencia as mas- 

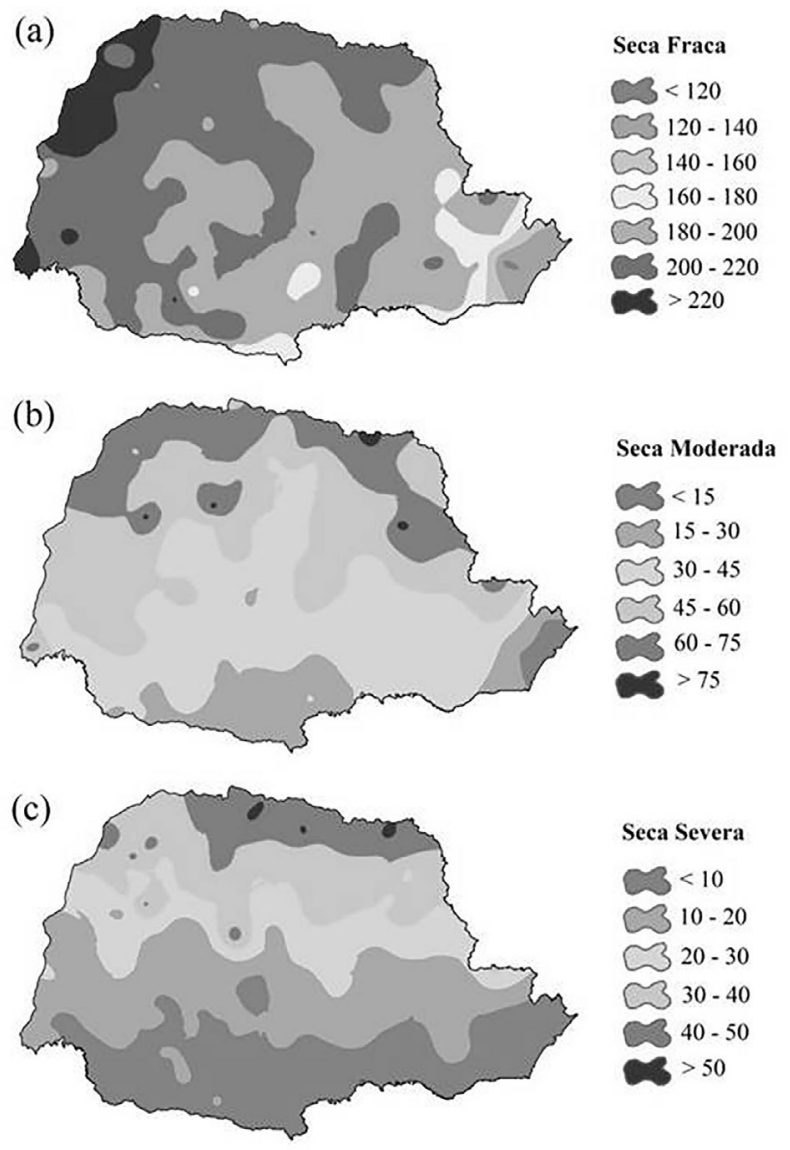

Figura 2 - Número total de ocorrência de períodos secos de intensidades fraca, moderada e severa. Paraná, 1977 a 2015.

sas de ar atuante em cada região. Segundo Sousa (2006) o menor índice de precipitação é registrado no noroeste do Paraná e ocorre devido a influência da continentalidade e dos sistemas meteorológicos atuantes naquela região. A autora relata ainda que um dos principais sistemas meteorológicos que atua no noroeste do Paraná é a massa Tropical continental, que tem origem no Grande Chaco - centro atmosférico de baixa pressão entre Paraguai, Brasil e Bolívia - o qual inibe muitas vezes a atuação das precipitações.

Por outro lado, regiões mais altas localizadas no sul do Paraná, como a Serra Geral, na região do município de Palmas e Guarapuava, e a Serrinha, na região de Ponta Grossa, apresentaram menores registros de períodos secos comparados à região noroeste (Fig. 2). Isso ocorreu porque naquela região há influência de sistemas meteorológicos que provocam altos índices de precipitações, como as constantes entradas de sistemas frontais associados ao jato subtropical da Alta da Bolívia - faixa de circulação anticiclônica na alta troposfera - e massas de ar quentes e úmidas como a massa Equatorial continental nas estações da primavera e verão e a Zona de Convergência do Atlântico Sul (ZCAS), que é um sistema meteorológico caracterizado pela persistência de uma banda de nebulosidade orientada no sentido noroeste-sudeste (NO-SE) associada a uma acentuada região de convergência. A ZCAS é característica da circulação de verão na América do Sul e sua atuação impacta no regime pluviométrico sobre grande parte do Brasil. Nas regiões próximas de sua posição climatológica podem ocorrer períodos intensos de precipitação (Sousa, 2006; Reboita et al., 2010). Esses sistemas meteorológicos estão associados à posição geográfica e relevo.

Observa-se que no litoral e nas localidades próximas a Serra do Mar apresentaram os menores índices de períodos secos (Fig. 2). De acordo com Fritzsons et al. (2011) isso ocorreu devido aos fatores condicionantes da chuva na Serra do Mar, tanto em mesoescala como em microescala, que se agregaram aos fatores sinóticos: orografia, terral, brisa marítima, águas interiores e contrastes térmicos entre terra e oceano. Essas chuvas orográficas são provocadas tanto pelas correntes de direção perpendicular ao relevo em escala sinótica de leste e sudeste, quanto pela brisa marítima observada no final da tarde e início da noite.

Wrege et al. (1999) também verificaram que as regiões nortes e noroestes paranaenses apresentam elevado risco de deficiência hídrica, enquanto que a região litorânea possui baixo risco. Costa et al. (2009) concluíram que no Paraná os maiores períodos secos ocorrem no norte do estado, seguido do oeste, centro, sul e litoral. Caramori et al. (2006) também encontraram maior duração de períodos secos no norte e menor no sul do Paraná. Fritzsons et al. (2011) observaram que o norte do Paraná foi a região com menor pluviometria do estado, enquanto que o sudoeste e o litoral foram os locais de maior índice pluviométrico.

O mapeamento das diferentes intensidades de períodos secos no Paraná (Fig. 1) indica que, apesar de registrar poucos períodos secos e na maioria curtos, constitui um grande problema para o Paraná dependendo da época do evento. Considerando que a principal atividade econômica do estado é a agricultura, períodos de 10 a 20 dias sem chuva, dependendo do estádio fenológico, pode afetar negativamente a produção e economia. As grandes culturas do estado do Paraná, como soja e milho, demandam elevado suprimento de água na fase de germinação, florescimento e enchimento dos grãos (EMBRAPA, 2013; Fietz; Urchei, 2002). De acordo com Caramori et al. (2006) períodos secos são recorrentes e constitui uma causa importante na redução da produção das safras agrícolas do Paraná, isso porque o estado está situado em uma região de transição com grande variabilidade climática interanual na precipitação.

$\mathrm{Na}$ análise mensal dos períodos secos, observa-se que nos meses mais frios (maio a agosto) ocorreram maior número de eventos, nas três intensidades analisadas (Figs. 34,5 ). Isso porque nesses meses a energia solar é menos intensa, com temperaturas mais amenas e con- 


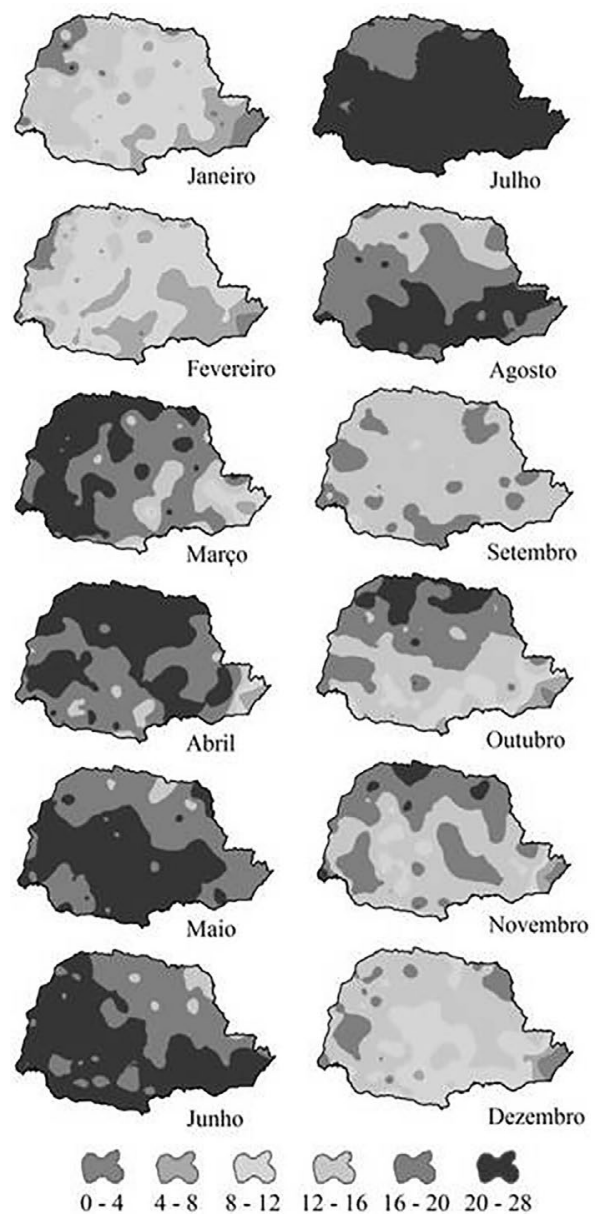

Figura 3 - Número mensal de ocorrência de períodos secos de intensidade fraca. Paraná, 1977 a 2015.

sequentemente menor capacidade de armazenamento de umidade na atmosfera e menor evapotranspiração. Essas condições meteorológicas provocam menores índices pluviométricos, portanto, maiores quantidades de períodos secos. Aliado a isso, as massas de ar que provocam chuvas no Paraná são menos atuantes nessa época devido à ocorrência constante de bloqueios atmosféricos, que são áreas de alta pressão que impedem a entrada de massas de ar e de sistemas frontais. A estabilidade é predominante e frequentemente ocorrem estiagens (Borsato, 2016). O contrário observou-se nos meses mais quentes (dezembro a fevereiro), que registraram as menores quantidades de períodos secos.

Quanto à espacialização mensal dos períodos secos no estado, de modo geral, as regiões situadas nas maiores latitudes, abrangendo litoral, sul e sudoeste, foram menos acometidas por seca em todas as intensidades analisadas. Isso ocorreu devido à forte atuação da massa de ar Polar atlântica nas regiões sul e sudoeste, que é o principal sistema atmosférico que desencadeia a precipitações no estado (Borsato, 2016). No litoral o sistema que provoca altos índices pluviométricos e consequentemente menor quanti-

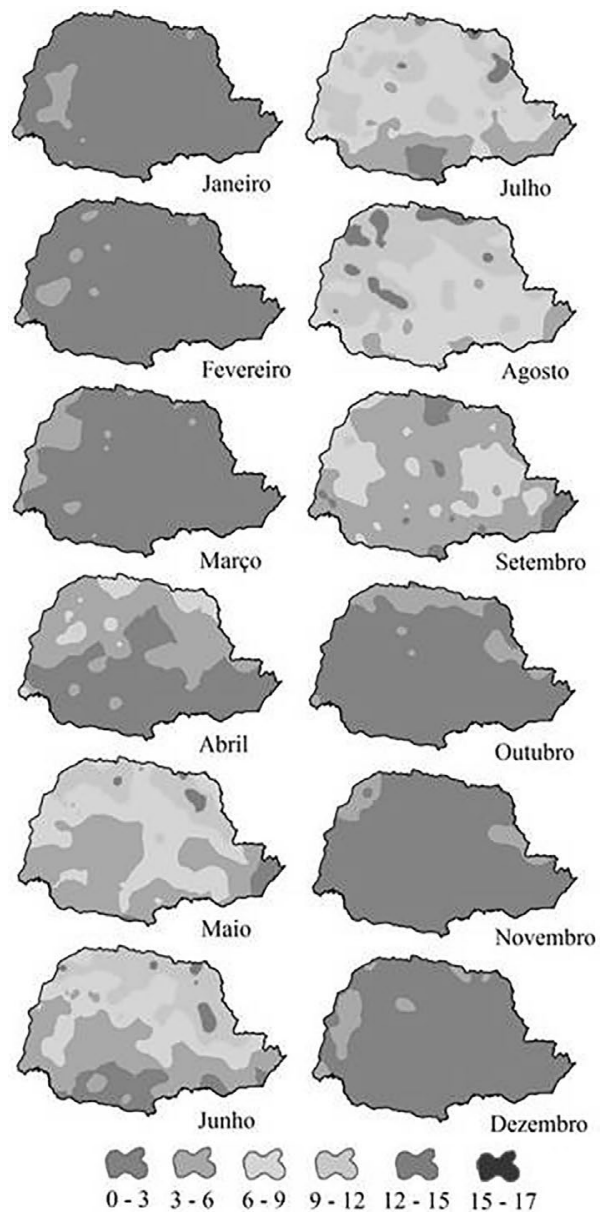

Figura 4 - Número mensal de ocorrência de períodos secos de intensidade moderada. Paraná, 1977 a 2015.

dade de períodos secos é a massa de ar Tropical atlântica associada ao efeito orográfico da Serra do Mar (Borsato, 2016).

Caramori et al. (2006) também observaram no Paraná predomínio de períodos secos no outono/inverno e menor ocorrência no verão. Na definição de zonas homogêneas de pluviometria no Paraná, Fritzsons et al. (2011) verificaram que no litoral as chuvas de verão são as mais expressivas em relação as demais estações. A precipitação no litoral está sujeita ao efeito orográfico, onde a convergência vertical de umidade influencia na precipitação de verão (Grimm, 2009a). Ferreira (2007), em estudo sobre estiagens no estado do Paraná no período de 1971 a 2004, concluiu que em grande parte dos municípios analisados houve maior concentração de chuvas na primavera/verão e menor pluviosidade no outono/inverno. De acordo com Fritzsons et al. (2011) as regiões de menores pluviometrias no Paraná são o norte e noroeste, onde o clima é mais seco, há estiagens no inverno em pelo menos um mês e as chuvas concentram-se no verão.

$\mathrm{Na}$ associação de períodos secos e eventos ENOS, observa-se que a maior frequência de secas foi registrada 


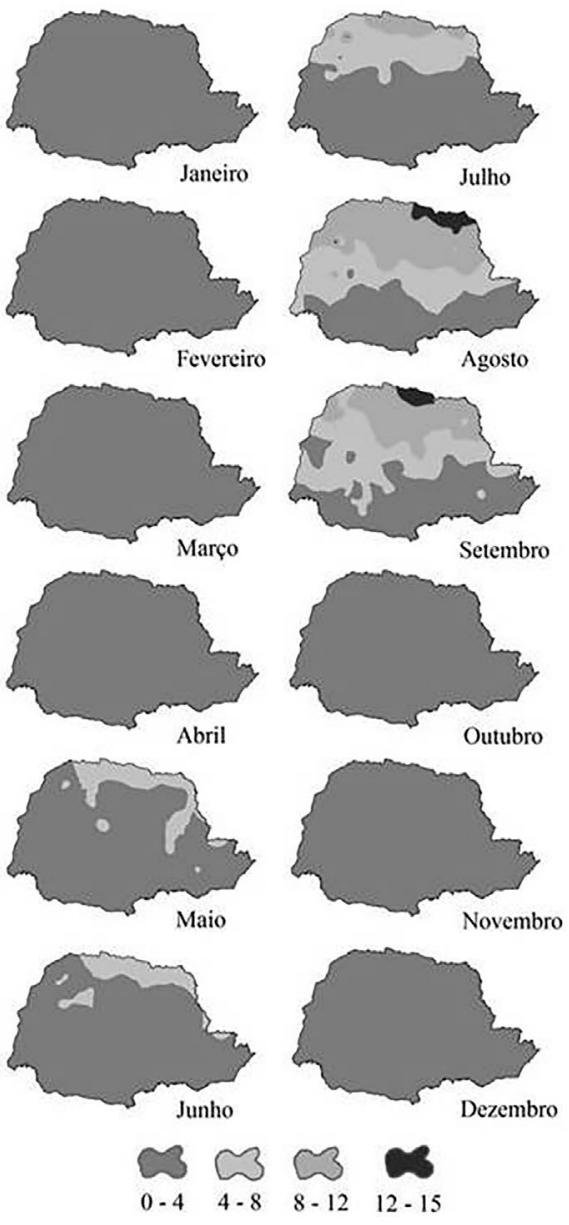

Figura 5 - Número mensal de ocorrência de períodos secos de intensidade severa. Paraná, 1977 a 2015.

na condição de neutralidade, ou seja, sem a influência dos Fenômenos La Niña e El Niño, nas três intensidades de secas analisadas (Fig. 6). Isso ocorreu porque durante os 39 anos deste estudo, independente dos períodos secos, a condição predominante foi de neutralidade (54\%) (Fig. 7).

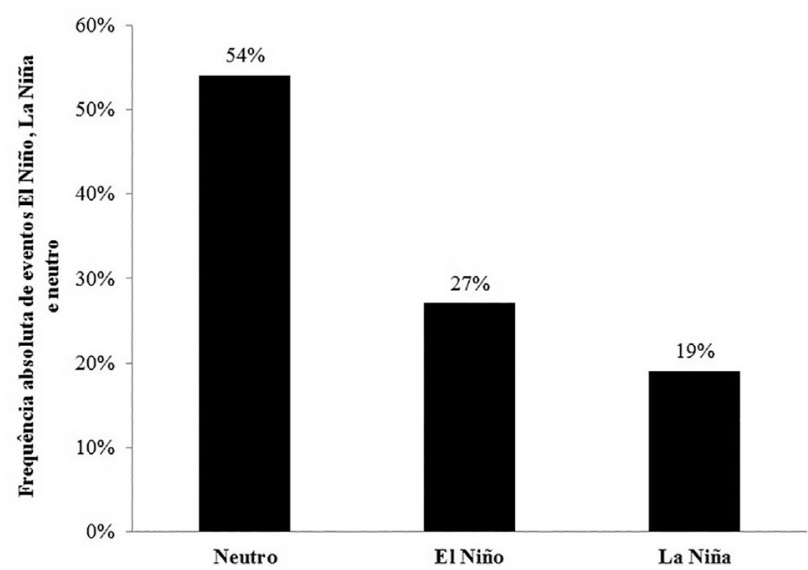

Figura 7 - Frequência absoluta de eventos El Niño, La Niña e neutralidade no período de 1977 a 2015.

Todavia, ao analisar a influência do El Niño ou La Niña, observa-se que houve um aumento da frequência de períodos secos na condição de La Niña à medida que aumentou a intensidade da seca (Fig. 6). Em anos de La Niña os ventos alísios tornam-se mais intensos e a célula de tipo Hadley enfraquece, fazendo com que os sistemas frontais se desloquem mais rapidamente pela região sul do Brasil, provocando precipitações abaixo da média climatológica nesta região (Berlato; Fontana, 2003; Cunha, 1999). Nota-se também que a ocorrência dessas secas moderadas e severas foi maior na condição de La Niña que na condição de El Niño, mesmo àquela apresentando menor incidência ao longo do período de estudo (19\%) independente dos períodos secos (Fig. 7). Nascimento Júnior (2011), em estudos sobre variabilidade interanual e decadal das chuvas no Paraná, constataram que a ocorrência do fenômeno La Niña coincidiu com anos secos no estado. Pessini (2017) e Teixeira et al. (2013) relatam que as secas mais severas ocorrem predominantemente em condição de La Niña.

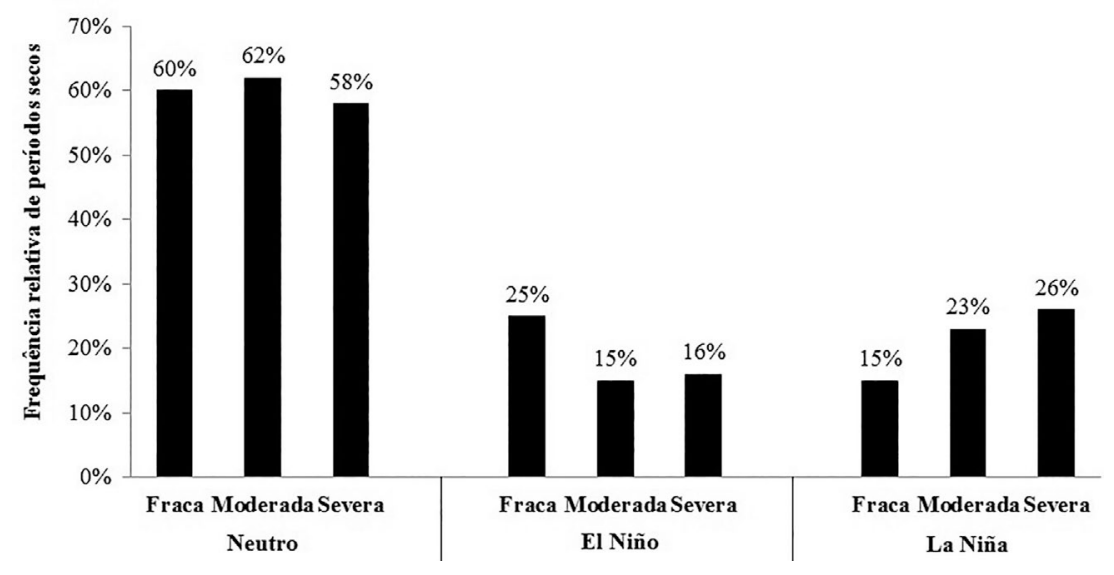

Figura 6 - Frequência relativa de períodos secos ocorridos nos eventos El Niño, La Niña e neutralidade para cada intensidade de seca. Paraná, 1977 a 2015. A porcentagem total (100\%) refere-se à soma de cada intensidade. 
Tabela 1 - Análise de regressão de períodos secos de intensidades fraca, moderada e severa. Paraná, 1977 a 2015.

\begin{tabular}{|c|c|c|c|}
\hline Mesorregiões & Seca Fraca & Seca Moderada & Seca Severa \\
\hline \multirow[t]{2}{*}{ Noroeste } & $y=0,003 x+5,495$ & $y=0,001 x+1,522$ & $y=0,005 x+0,749$ \\
\hline & $\mathrm{R}^{2}=0,001$ & $\mathrm{R}^{2}=0,000$ & $\mathrm{R}^{2}=0,006$ \\
\hline \multirow[t]{2}{*}{ Centro Ocidental } & $y=-0,009 x+5,311$ & $y=0,002 x+1,169$ & $y=0,001 x+0,593$ \\
\hline & $\mathrm{R}^{2}=0,008$ & $\mathrm{R}^{2}=0,001$ & $\mathrm{R}^{2}=0,000$ \\
\hline \multirow[t]{2}{*}{ Norte Central } & $\mathrm{y}=0,001 \mathrm{x}+5,272$ & $y=-0,004 x+1,513$ & $y=-0,004 x+1,077$ \\
\hline & $\mathrm{R}^{2}=0,000$ & $\mathrm{R}^{2}=0,004$ & $\mathrm{R}^{2}=0,004$ \\
\hline \multirow[t]{2}{*}{ Norte Pioneiro } & $y=0,008 x+4,999$ & $y=0,003 x+1,543$ & $y=0,001 x+0,936$ \\
\hline & $\mathrm{R}^{2}=0,005$ & $\mathrm{R}^{2}=0,002$ & $\mathrm{R}^{2}=0,000$ \\
\hline \multirow[t]{2}{*}{ Centro Oriental } & $y=0,004 x+4,873$ & $y=-0,002 x+1,297$ & $y=-0,003 x+0,595$ \\
\hline & $\mathrm{R}^{2}=0,003$ & $\mathrm{R}^{2}=0,001$ & $\mathrm{R}^{2}=0,007$ \\
\hline \multirow[t]{2}{*}{ Oeste } & $y=-0,003 x+5,527$ & $y=-0,001 x+1,265$ & $y=0,003 x+0,286$ \\
\hline & $\mathrm{R}^{2}=0,001$ & $\mathrm{R}^{2}=0,000$ & $\mathrm{R}^{2}=0,01$ \\
\hline \multirow[t]{2}{*}{ Sudoeste } & $\mathrm{y}=0,001 \mathrm{x}+5,048$ & $\mathrm{y}=0,000 \mathrm{x}+0,787$ & $y=-0,001 x+0,197$ \\
\hline & $R^{2}=9 E-05$ & $\mathrm{R}^{2}=6 \mathrm{E}-05$ & $\mathrm{R}^{2}=0,004$ \\
\hline \multirow[t]{2}{*}{ Centro-Sul } & $y=-0,009 x+5,159$ & $y=-0,000 x+0,823$ & $y=-0,005 x+0,330$ \\
\hline & $\mathrm{R}^{2}=0,006$ & $\mathrm{R}^{2}=6 \mathrm{E}-05$ & $\mathrm{R}^{2}=0,033$ \\
\hline \multirow[t]{2}{*}{ Sudeste } & $y=0,005 x+4,873$ & $y=-0,000 x+0,881$ & $y=-0,005 x+0,388$ \\
\hline & $\mathrm{R}^{2}=0,002$ & $\mathrm{R}^{2}=2 \mathrm{E}-05$ & $\mathrm{R}^{2}=0,044$ \\
\hline \multirow[t]{2}{*}{ Metropolitana } & $y=-0,009 x+4,718$ & $y=0,006 x+0,849$ & $y=-4 E-05 x+0,282$ \\
\hline & $\mathrm{R}^{2}=0,008$ & $\mathrm{R}^{2}=0,016$ & $\mathrm{R}^{2}=3 \mathrm{E}-06$ \\
\hline
\end{tabular}

Na condição de El Niño observa-se que houve maior frequência de secas de intensidade fraca (Fig. 6). Os eventos de El Niño são notadamente marcados por grandes quantidades de precipitação no sul do Brasil devido à intensificação dos sistemas atmosféricos dinâmicos que atuam na região, como os sistemas frontais. Em condições de El Niño, a corrente de jato subtropical tem seu posicionamento médio alterado, influenciado pelas mudanças nos padrões da atmosfera superior, refletindo na intensificação dos processos geradores de chuvas (Parizotto, 2008). Assim, ocorrem períodos secos de duração mais curta nesta condição de ENOS.

Quanto à análise temporal, observa-se que as equações e os valores de R2 foram muito baixos, indicando que não houve tendência de aumento ou redução de períodos secos nas diferentes intensidades e mesorregiões do Paraná nos 39 anos de dados registrados (Tabela 1). Em estudos climatológicos no Paraná com série de dados de 48 a 116 anos, Minuzzi e Caramori (2011) observaram que a quantidade de chuva tem aumentado na metade leste do estado e as demais regiões não apresentaram alterações quantitativas da precipitação. Tais resultados corroboram com o presente trabalho, uma vez que, se os índices de precipitação estão aumentando ou permanecendo inalterados, infere-se que os períodos secos tampouco aumentem ou alterem. Em adição, aqueles autores também observaram redução na ocorrência de veranicos com duração de cinco dias na primavera. A precipitação é um elemento meteorológico de alta variabilidade espacial e temporal (Britto et al., 2008; Ashraf et al., 2013), especialmente no Paraná, que está localizado em uma região de transição climática e sofre influência de várias massas de ar. Por isso, para estudos climatológicos de tendência de seca decorrente das mudanças climáticas, é desejável séries de dados mais extensas que a apresentada neste estudo. Costa et al. (2009) e Caramori (2006) analisando períodos secos no Paraná, também não detectaram tendência de redução ou aumento de episódios de seca em diversos municípios do estado.

\section{Conclusões}

O estado do Paraná possui regiões diferenciadas quanto aos períodos secos, influenciadas pela condição geográfica e dinâmica da circulação atmosférica. A ocorrência de períodos secos diminui à medida que aumenta sua duração. A ocorrência de períodos secos é mais expressiva na região norte e menos no litoral e sul do estado. Os períodos secos ocorrem com maior frequência nos meses mais frios (maio a agosto). As secas severas e moderadas ocorrem mais frequentemente na condição de La Niña, enquanto que as mais fracas são registradas na 
condição de El Niño. Não há tendência temporal de aumento ou redução do número de períodos secos no Paraná.

\section{Referências}

ASHRAF, B.; YAZDANI, R.; MOUSAVI-BAYGI, M.; BANNAYAN, M. Investigation of temporal and spatial climate variability and aridity of Iran. Theoretical and Applied Climatology, v. 118, p. 35-46, 2013.

ASSAD, E.D.; MASUTOMO, R.; SANO, E.E.; CASTRO, L.H.; SILVA, F.M. Veranico na região dos cerrados brasileiros: Freqüência e probabilidade de ocorrência. Pesquisa Agropecuária Brasileira, v. 28, n. 9, p. 993-1003, 1993.

BERLATO, M.A.; FONTANA, D.C. EI Niño e Laniña: Impactos no Clima, na Vegetação e na Agricultura do Rio Grande do Sul: Aplicações de Previsões Climáticas na Agricultura. Porto Alegre: UFRGS, 110 p., 2003.

BORSATO, V.A. A Dinâmica Climática do Brasil e Massas de Ares. Curitiba: Editora CRV, 181 p., 2016.

BRITTO, F.P.; BARLETTA, R.; MENDONÇA, M. Variabilidade espacial e temporal da precipitação pluvial no Rio Grande do Sul: influência do fenômeno El Niño Oscilação Sul. Revista Brasileira de Climatologia, v. 3, p. 37-48, 2008.

CARAMORI, P.H.; OLIVEIRA, D.; CAVIGLIONE, J.H.; BORROZZINO, E. Análise Histórica do Clima Paranaense, 2006. Disponível em http://www.iapar.br/arquivos/File/ zip_pdf/analise6.pdf, acesso em 5 jun. 2017.

CARVALHO, A.L.; SOUZA, J.L.; LYRA, G.B.; PORFIRIO, A.C.S. Ocorrência de períodos secos na região de Rio Largo, Alagoas. Revista Brasileira de Meteorologia, v. 28, n. 2, p. 173-180, 2013.

COMMITTEE FOR ECONOMIC DEVELOPMENT OF AUSTRALIA (CEDA). The Economics of Climate Change, 2014. Disponivel em http://adminpanel.ceda.com.au/ FOLDERS/Service/Files/Documents/22090 Economicsof-Climate-Change.pdf, acesso em 5 jun. 2017.

COSTA, A.B.F.; MORAIS, H.; CARAMORI, P.H.; RICE, W.S.; ATAÍDE, L.T.; YADA, I.F.U. Análise climatológica de dias consecutivos sem chuva no Estado do Paraná. In: Anais III Simpósio Internacional de Climatologia. Canela, 2009.

CUNHA, G.R. Oscilação do Sul e perspectivas climáticas aplicadas no manejo de culturas no sul do Brasil. Revista Brasileira de Agrometeorologia, v. 7, n. 2, p. 277-284, 1999.

EMPRESA BRASILEIRA DE PESQUISA AGROPECUÁRIA (EMBRAPA). Tecnologias de Produção de Soja - Região Central do Brasil 2014. Londrina: Embrapa Soja, 265 p., 2013.

FARIAS, J.R.B. Zoneamento agroclimático delimita áreas de risco para soja. Visão Agrícola, v. 5, p. 70-72, 2006.

FERREIRA, M.E. Estiagens no Estado do Paraná 1971-2004. Dissertação de Mestrado em Geografia, Universidade Federal do Paraná, Curitiba, 148 p., 2007.

FIETZ, C.R.; URCHEI, M.A. Deficiência hídrica da cultura da soja na região de Dourados, MS. Revista Brasileirade Engenharia Agrícola e Ambiental, v. 6, p. 262-265, 2002.

FRITZSONS, E.; MANTOVANI, L.E.; WREGE, M.S.; CHAVES NETO, A. Análise da pluviometria para definição de zonas homogêneas no Estado do Paraná. RA'EGA - O Espaço Geográfico em Análise, v. 23, p. 555-572, 2011.

GRIMM, A.M. Clima da região sul do Brasil. In: Tempo e Clima no Brasil. CAVALCANTI, I.F.A.; FERREIRA, N.J.; DIAS, M.A.F.S; SILVA, M.G.A.J. (eds) São Paulo: Oficina de Textos, p. 259-275, 2009a.

GRIMM, A.M. Variabilidade interanual do clima no Brasil. In: Tempo e Clima no Brasil. CAVALCANTI, I.F.A.; FERREIRA, N.J.; DIAS, M.A.F.S; SILVA, M.G.A.J. (eds) São Paulo: Oficina de Textos, p. 259-275, 2009b.

HOOGENBOOM, G. Contribution of agrometeorology to the simulation of crop production and its applications. Agricultural land Forest Meteorology, v. 103, p. 137-157, 2000.

KOBIYAMA, M.; MENDONÇA, M.; MORENO, D.A.; MARCELINO, I.P.V.O.; MARCELINO, E.V.; GONÇALVES, E.F.; BRAZETTI, L.L.P.; GOERL, R.F.; MOLLERI, G.S.F.; RUDORFF, F.D. Prevenção de Desastres Naturais: Conceitos Básicos. Florianópolis: Ed. Organic Trading, 110 p., 2006.

LEAL, A.J.F.; HORA, R.C.; TONIN, T.A.; BOLIANI, A.C. Viabilidade econômica do cultivo de abacaxi no arenito Caiuá, região noroeste do Estado do Paraná. Acta Scientiarum: Agronomy, v. 31, n. 2, p. 353-358, 2009.

MENDONÇA, F.; DANNI-OLIVEIRA, I.M. Climatologia: Noções Básicas e Climas do Brasil. São Paulo: Oficina de Textos, 2007.

MINISTÉRIO DA AGRICULTURA, PECUÁRIA E ABASTECIMENTO (MAPA). Zoneamento Agrícola de Risco Climático. Disponível em: http://indicadores.agricultura.gov. br/zarc/index.htm, acesso em 7 jun. 2017.

MINUZZI, R.B.; CARAMORI, P.H. Variabilidade climática sazonal e anual da chuva e veranicos no Estado do Paraná. Rev. Ceres, v. 58, n. 5, p. 593-602, 2011.

MOTA, F.S.; AGENDES, M.O.O. Clima e Agricultura no Brasil. Porto Alegre: SAGRA, 151 p., 1986.

NASCIMENTO JÚNIOR, L. As Chuvas no Paraná: Variabilidade Interanual e Decadal. Monografia de Graduação em Geografia, Universidade Estadual de Londrina, Londrina, 90 p., 2011.

NASCIMENTO JÚNIOR, L.; SANT'ANNA NETO, J.L. Contribuição aos estudos da precipitação no Estado do Paraná: a oscilação decadal do pacífico - ODP1. RA'EGA - O Espaço Geográfico em Análise, v. 35, p. 314-343, 2015.

NATIONAL OCEANIC AND ATMOSPHERIC ADMINISTRATION (NOAA).Cold and Warm Episodes by Season. 2016. Disponível em http://www.cpc.ncep.noaa.gov/ products/analysis_monitoring/ensostuff/ensoyears.shtml, acesso em 7 dez. 2016.

NIMER, E. Climatologia do Brasil. 2. ed. Rio de Janeiro: IBGE, 421 p., 1989.

OLIVEIRA, L.C.; ANDRADE, E.M.; CHAVES L.C.G.; FERNANDES, F.B.P. Frequência e distribuição espacial de veranicos no estado do Ceará. In: Anais $2^{\circ}$ Simpósio Brasileiro de Recursos Naturais do Semiárido. Quixadá: Universidade Federal do Ceará, p. 1-6, 2015.

PARIZOTTO, T.M. Análise da Precipitação Pluvial na Bacia do Paranapanema. Monografia de Graduação em Geografia, Universidade Estadual Paulista, Ourinhos, 75 p., 2008. 
PESSINI, P.B. Estudo dos Eventos de Seca Meteorológica na Região Sul do Brasil. Monografia de Graduação em Engenharia Sanitária e Ambiental, Universidade Federal de Santa Catarina, Florianópolis, 88 p., 2017.

PSCHEIDT, I. Influência de Episódios El Niño e La Niña na Frequência de Eventos Extremos de Precipitação no Sul do Brasil. Dissertação de Mestrado em Meteorologia, Universidade de São Paulo, São Paulo, 167 p., 2006.

REBOITA, M.S.; GAN, M.A.; ROCHA, R.P. da.; AMBRIZZI, T. Regimes de precipitação na América do Sul: uma revisão bibliográfica. Rev. Bras. Meteorol., v. 25, n. 2, p. 185-204, 2010.

ROPELEWISKY, C.F.; HALPERT, M.S. Precipitation patterns associated with the right index phase of the southern oscillation. Journal of Climate, v. 2, p. 268-284, 1989.

SALINI, M.F. A influência do fenômeno El Niño Oscilação Sul - ENOS (La Niña e EI Niño) na Ocorrência de Inundações no Vale do Taquari - RS. Monografia de Graduação em Engenharia Ambiental, UNIVATES, Lajeado, 56 p., 2011.

SCHIERMEIER, Q. The costs of global warming. Nature, v. 439, p. 374-375, 2006.

SOUSA, P. Estudo da Variabilidade da Precipitação no Estado do Paraná Associado à Anomalia da TSM no Oceano
Pacífico. Dissertação de Mestrado em Geografia, Universidade Estadual de Maringá, Maringá, 72 p., 2006.

STOKSTAD, E. States sue over global warming. Science, v. 305, p. 590, 2004.

TEIXEIRA, C.F.A.; DAMÉ, R.C.F.; BACELAR, L.C.S.; SILVA, G.M.; COUTO, R.S. Intensidade da seca utilizando índices de precipitação. Ambiente \& Água, v. 8, n. 3, p. 204-213, 2013.

VANHONI, F.; MENDENÇA, F. O clima do litoral do Estado do Paraná. Revista Brasileira de Climatologia, v. 3, p. 49-63, 2008.

WORLD METEOROLOGICAL ORGANIZATION (WMO). Drought Assessment and Forecasting. 2005. Disponível em http:/www.wmo.int/pages/prog/hwrp/documents/ regions/DOC8.pdf, acesso em 20/02/2018.

WREGE, M.S.; GONÇALVES, S.L.; CARAMORI, P.H.; VASCONCELLOS, M.E.C.; OLIVEIRA, D.; ABUCARUB NETO, M.; BORROZZINO, E.; CAVIGLIONE, J.H. Risco de deficiência hídrica na cultura do milho no Estado do Paraná. Pesquisa Agropecuária Brasileira, v. 34, n. 7, p. 1119-1124, 1999.

License information: This is an open-access article distributed under the terms of the Creative Commons Attribution License (type CC-BY), which permits unrestricted use, distribution and reproduction in any medium, provided the original article is properly cited. 